\section{WHARTON ON MANAGING EMERGING TECHNOLOGIES}

De George S. Day, Paul J. H. Schoemaker e Robert E. Gunther New York : John Wiley \& Sons, 2000. 460 p.

Por Tânia Limeira, Professora do Departamento de Mercadologia da FGV-EAESP. E-mail: tanial@fgvsp.br

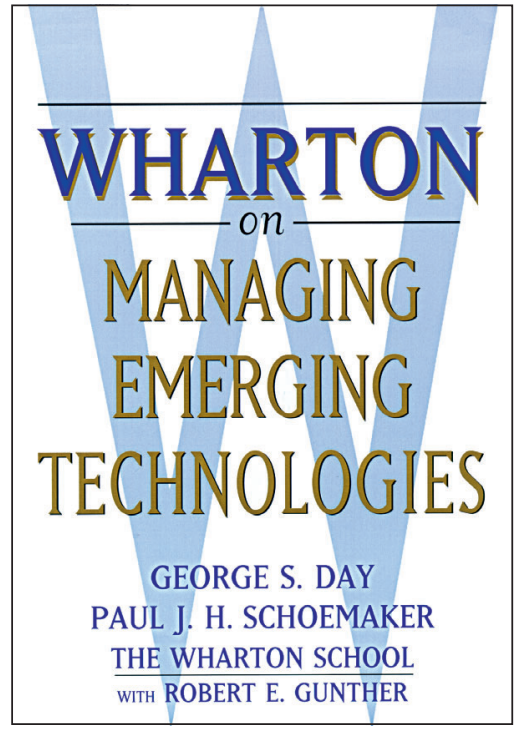

livro examina os desafios da gestão das tecnologias emergentes, as inovações baseadas na tecnologia da informação, na biotecnologia e outras áreas da Ciência, que estão criando e reestruturando indústrias numa velocidade sem precedentes, tornando obsoletas as antigas práticas de gestão e exigindo novas competências e estratégias.

O objetivo dos autores, um grupo de pesquisadores e professores do Programa "Wharton Emerging Technologies Management Research", surgido em 1994, na University of Pennsylvania, EUA, é o de oferecer, sob a perspectiva da alta administração, uma análise dos desafios da gestão das tecnologias emergentes, que envolvem todas as áreas da organização como finanças, alianças estratégicas, empreendedorismo, teoria de rede, estratégia, marketing, recursos humanos, etc.

As questões-chave discutidas são: como antecipar as novas tendências e as novas políticas públicas que darão forma aos mercados emergentes? Que mudanças os gestores devem fazer em suas abordagens e práticas nas áreas de análise financeira, estratégias competitivas, parcerias estratégicas, gestão de competências e sistemas organizacionais?

O livro é o resultado dos debates realizados entre os pesquisadores e 20 executivos de empresas líderes de mercado. Esse intercâmbio entre a academia e a prática empresarial possibilitou que os autores estruturassem um conjunto de fatores críticos - sete no total - que norteiam o desenvolvimento da obra, visto que não há um modelo ou paradigma preestabelecidos para a análise da gestão de tecnologias emergentes.

O primeiro fator crítico é a avaliação das tecnologias emergentes, que aprofunda a análise de como as empresas tomam decisões perante o alto grau de incerteza e as rápidas mudanças de competências exigidas que caracterizam essas tecnologias. São investigados os caminhos que as empresas percorrem para o desenvolvimento de tecnologias, os referenciais utilizados para avaliação e o papel do governo no surgimento de novas indústrias, ao desempenhar a função de financiador de projetos e pesquisa e de regulamentador dos produtos e serviços.

O segundo fator trata do desenvolvimento e da gestão de alianças estratégicas, investigando como as empresas em parceria podem alavancar suas forças e competências para atingirem benefícios mútuos. Aqui se analisa o impacto das redes de conhecimento, formais e informais, para a criação e a difusão dos novos padrões tecnológicos, já que tecnologias emergentes são desenvolvidas por redes de indivíduos ou empresas, e não por indivíduos ou empresas isoladas. Procura-se expor como mapear as re- 
des existentes, entender suas dinâmicas, bem como criar novas redes, fortalecê-las e gerenciá-las. O conceito central é o da teoria de gráficos (graph theory), um ramo da matemática utilizado para analisar o funcionamento das redes de conhecimento, identificando os atores envolvidos, os mecanismos pelos quais estão ligados entre si e os processos de otimização desses intercâmbios.

A análise das estratégias de tecnologia é o terceiro fator analisado, discutindo como as empresas decidem sobre as estratégias alternativas de aquisição, licenciamento e desenvolvimento próprio, avaliando os riscos, vantagens e desvantagens de cada alternativa. Considera-se a importância de combinar disciplina e imaginação e o uso de cenários de planejamento. São examinados os dez passos para a construção de cenários e como analisá-los para identificar os fracos sinais de futuras mudanças significativas nos mercados e para visualizar o impacto das descontinuidades tecnológicas nos modelos de negócios vigentes na empresa. É demonstrado como a elaboração de cenários pode possibilitar a redução da resistência às novas idéias, na medida em que sejam vistos como oportunidades de aprendizado, para gerar novos insights sobre o impacto das inovações nos mercados, na concorrência e nos consumidores.

O processo de desenvolvimento de novos produtos para novos mercados, quarto fator crítico, trata de investigar como as empresas desenvolvem suas habilidades em criar conceitos de produtos altamente inovadores com base em tecnologias emergentes e lidam com as ambigüidades do mercado potencial, exigências dos clientes e forças competitivas. Discute-se o desafio para o estrategista em desenvolver tecnologia que permita o contínuo aperfeiçoamento do conjunto de atributos dos produtos de modo lucrativo, estando o sucesso relacionado ao grau em que um dado conjunto de atributos torna-se o preferido pelos usuários. Também é examinado o processo de comercialização das inovações tecnológicas, discutindo-se a importância da construção de ativos complementares que capacitam a empresa a criar condições únicas para a comercialização e difusão da inovação no mercado, como acesso a rede de distribuidores, prestadores de serviços, relacionamentos com fornecedores e clientes e produtos de terceiros complementares aos seus.

Moldar organizações para competir em tecnologias emergentes é o quinto fator crítico e trata das alternati- vas de desenho organizacional que tornam as empresas capazes de desenvolver e comercializar tecnologias emergentes, discutindo programas de incentivos e recompensas que estimulam o surgimento de inovadores, empreendedores e líderes dentro da organização. Nesse tópico, os autores relatam como desenvolver organizações mais dinâmicas, flexíveis e adaptáveis, abordando novos desenhos e formatos, como as organizações virtuais, em que os colaboradores, fornecedores e clientes estão geograficamente dispersos, porém conectados pela tecnologia, ou a organização em rede, baseada em um conjunto de relacionamentos entre unidades de trabalho autônomas ou semi-autônomas, responsáveis pela elaboração e entrega de produtos e serviços para os clientes, ou os spin-outs, que são pequenas organizações formadas dentro de outras organizações maiores para desenvolver novas tecnologias, que se tornam parcialmente autônomas, com a empresa-mãe atuando no papel de investidora, mentora ou incubadora.

O sexto fator crítico é a gestão da propriedade intelectual, que discute como as empresas identificam as oportunidades de aquisição de propriedade intelectual e os meios de estabelecer o seu valor e protegê-la da perda para concorrentes ou parceiros. São investigadas as alternativas de estratégia para apropriação dos ganhos gerados pela inovação tecnológica, analisando as limitações da proteção oferecida pelas patentes e examinando outros mecanismos como secrecy, entendido como um mecanismo particular de proteção que o proprietário pode obter sem a interferência do governo, por meio de práticas gerenciais ou características do produto que impedem, por exemplo, a engenharia reversa; ou a vantagem oferecida pelo lead time, que vem a ser o período de tempo que transcorre para surgir uma outra empresa que copie a inovação.

O sétimo e último fator é a evolução das indústrias baseadas em tecnologias emergentes, que investiga como esse tipo de indústria se diferencia das tradicionais, como surgem e evoluem e quais são as melhores práticas, estratégias e fatores de sucesso.

Com um conteúdo denso, porém escrito de forma leve e interessante, o livro propicia, portanto, uma estimulante reflexão sobre os novos desafios a serem enfrentados pelos gestores, provocando o pensamento criativo para a busca de soluções aos novos problemas e para a pesquisa de novos caminhos que permitam aproveitar as oportunidades criadas pelas inovações tecnológicas. $\bigcirc$ 